\title{
Does the Prevalence of Anatomical Variants of the Brain Ventricles vary according to Socioeconomic Status? A Cross-sectional Imaging Survey in 2 Brazilian Private Hospitals
}

\section{Lia Pontes Lisboa Martins}

Universidade Federal do Ceará

Paulo Marcelo Gondim Sales

University of Alabama

Adriana de Menezes Gomes

Centro Universitário Unichristus

Marlon Sousa Silva

Centro Universitário Unichristus

Gabriela de Andrade Meireles Bezerra

Centro Universitário Unichristus

Francisco de Assis Aquino Gondim ( $\sim$ gondimfranc@gmail.com )

Universidade Federal do Ceará

\section{Research Article}

Keywords: Cavum Septum Pellucidum, Cavum Vergae, Neurodevelopmental disorders, Computerized Tomography, Prevalence

Posted Date: September 14th, 2021

DOl: https://doi.org/10.21203/rs.3.rs-777158/v1

License: (c) (i) This work is licensed under a Creative Commons Attribution 4.0 International License. Read Full License 


\section{Abstract}

Background: Anatomical variants of brain ventricles are a known marker for abnormal central nervous system development. They seem to be more prevalent in several neuropsychiatric disorders, e.g. schizophrenia, personality disorders, and psychosis. However, knowledge about the risk factors and their overall prevalence in the general population, especially in developing countries is still limited.

Methods. We evaluated the prevalence of prevalence of anatomical ventricular variants [Cavum septum pellucidum (CSP), Cavum vergae (CV), and Cavum velum interpositi (CVI)] in 1467 multislice head CTs from two large private hospitals in the city of Fortaleza, Ceará - Brazil.

Results. Hospital one had a higher percentage of patients with low-cost health insurance, strokes, and neurocysticercosis $(P<0.05)$. 15.1\% of participants in hospital one versus $7.1 \%$ in hospital two had at least one type of cerebral cavum, including vestigial CSP. The rarest types of cava (CV and CVI) were twice more common in hospital one $(P<0.05)$. Logistic regression analysis confirmed that patients from hospital one, older patients, and men were more likely to have any type of cerebral cavum and CSP.

Conclusions: Anatomical brain ventricular variants (including vestigial CSP) were present in about $12 \%$ of participants of this middle-class Brazilian sample while also being more prevalent in male elderly and participants from lower socioeconomic strata. Further studies are necessary to prospectively investigate the association between socioeconomic variables and how they relate to the prevalence of anatomical brain ventricular variants and other known risk factors for developmental disorders.

Trial registration: This study was approved by the Institutional Review Board from both participants institutions- Research Ethics Committee (CEP) - Unichristus (Protocols 099/11 and CAAE: 58763716.3.0000.5049).

\section{Introduction}

The Septum Pellucidum (for the Latin "translucent wall") is a thin membrane formed by two laminae (layers) of white and gray matter, delicately fused or superimposed[1]. It divides the right and left frontal horns from the lateral ventricles and runs as a sheet from the corpus callosum to the fornix. As part of the septohippocampal and limbic systems, it may be involved in complex behavioral functions not fully understood[1-4]. During early brain formation, there is a space between the two laminae forming a cavity, the Cavum Septum Pellucidum (CSP). The CSP usually develops at the $17^{\text {th }}-20^{\text {th }}$ week of gestation and is generally considered absent in at least $85 \%$ at birth or during early infancy $[5,6]$. Whenever it continues longitudinally at the level of the interventricular foramen, it starts to be called Cavum Vergae (CV). Throughout the first 6 months after birth, the CSP shrinks posteriorly to anteriorly due to the growth of the corpus callosum, fornix, frontal lobes, and other nearby limbic structures [2, 5, 7-9]. However, in some individuals, the septum pellucidum layers do not merge adequately and remain separated, from distances varying from 2 up to greater than $10 \mathrm{~mm}[10]$. The latter examples may cause obstructive symptoms by occlusion of the foramen of Monro[11, 12]. Despite the existence of several theories attempting to explain 
the persistence of the CSP $[4,13-16]$, there is no definite agreement on the mechanisms heralding its persistence.

Vestigial CSP, measuring between 1-4 mm are so prevalent and "universally ignored" even in studies evaluating the prevalence of CSP that according to Nopoulos et al (1997)[7] they should be considered a normal neuroanatomical variant. However, larger CSP are abnormal variants and markers for abnormal brain development[17][18]. Some studies have found possible associations between its persistence and psychiatric disorders, such as schizophrenia[18-23], psychosis[24, 25], personality disorders[26], mood disorders $[22,23,27]$. However, most associations are still not entirely accepted and further confirmation is still warranted.

Given that knowledge about possible risk factors and the overall prevalence of the CSP persistence in the general population is still limited, especially in developing countries, this study aimed to compare the prevalence and demographic factors associated with persistent CSP detected by brain imaging in patients from two private hospitals in the city of Fortaleza, Ceará, Brazil. Part of this study was reported in abstract form elsewhere[28].

\section{Subjects And Methods}

\section{Population}

We analyzed 1,467 consecutive multislice head CTs from two large private hospitals in the city of Fortaleza, Ceará - Brazil to compare the prevalence of different neurological diseases and neurological findings (including neuroanatomical variants), with a focus on the evaluation of the presence of CSP and its variants. Although both private hospitals primarily managed health insured (no government sponsorship) and only very few direct fee-for-service patients, socioeconomic differences were presumably present in both samples, as confirmed by the distribution of different insurance plans held by patients from both hospitals (i.e., high versus low-cost healthcare insurance plans). Both institutions are important private tertiary centers and none have inpatient psychiatric care.

\section{Data collection}

All details from medical records including demographic data and reason for performance of neuroimaging testing were collected from all patients and properly deidentified to ensure patient privacy. A standardized radiologic evaluation form was developed to document different findings observed in both institutions, which served as the main assessment tool. Patients were also further grouped according to the reason for head CT (head trauma or other reasons), as the subset evaluated for traumatic brain injury $(T B D)$ mimics a general population sampling, unlike those who are being investigated for a specific neurological condition (e.g., assessment of neurological deficits, strokes). As TBI was the main reason for head CT in hospital one, additional patients who underwent CT for TBI evaluation were selected in hospital two to address sampling differences. 
CSP was defined as the presence of a triangle image with cerebrospinal fluid density between the frontal horns and was further divided into two subtypes: 1. Vestigial CSP and 2. CSP proper. Subsequently, measurements were conducted in the axial view to evaluate the length and width of the CSP. This classification was based on the dimensions proposed by Nopoulos et al (1998)[29] and Filipović and Teofilovski-Parapid (2004)[30]. CV was defined as present when it did extend posteriorly until reaching the foramen of Monro. Additionally, we separately evaluated the presence of Cavum Velum Interpositi (CVI) and sole $\mathrm{CV}$, without concomitant CSP. Isolated CV was present whenever the septum pellucidum was normally organized, with fused laminae anteriorly, but separated posteriorly after the level of the foramen of Monro. CVI was present, whenever a triangle image in the region posterior and inferior at the level of the posterior horns of the lateral ventricles was evidenced.

In hospital one (Hospital Regional da Unimed, Fortaleza, Ceará), information from 1,016 consecutive patients was collected in 2012, while 451 patients were evaluated from July 2015 to July 2016 in hospital two (Hospital São Carlos, Fortaleza, Ceará). A total of 301 participants were randomly selected in an electronic list of CT performed on random days of the specified period, while 150 matched patients were selected for evaluation of TBI.

\section{Ethical aspects}

This study was approved by the Institutional Review Board from the Research Ethics Committee (CEP) of the Centro Universitário Unichristus (Protocols 099/11 and CAAE: 58763716.3.0000.5049), that granted permission to evaluate all demographic and radiological details from all patients. The Research Ethics Committee (CEP) - Centro Universitário Unichristus provided waiver of informed consent since data was collected from institutional databanks. Data collection for this study respected the principles of research involving human beings, according to all regulatory guidelines and norms.

\section{Statistical analysis.}

Patients were grouped according to hospital and reason for head CT. Sociodemographic differences among age were compared using Wilcoxon, while Fischer exact test compared differences among the remainder demographic factors (gender, age, presence of TBI, type of healthcare insurance) with a $\mathrm{P}<0.05$ for statistical significance. A subsequent regression analysis was used to assess the influence of different variables on the prevalence of CSP and subtypes. For this purpose, age was stratified into 3 groups: age 18-40, age 41-71, and $>72$.

\section{Results}

As observed in Table 1, both hospitals had a predominance of older females that was not significantly different between institutions. Among the first 301 head CTs from Hospital two, 23.9\% ( $N=72 / 301)$ evaluated TBI, and thereafter, more patients with TBI were selected to match the percentage of patients with TBI between the 2 hospitals. Patients with high-cost health insurance comprised $42.6 \%$ of hospital 
one and $60.8 \%$ of hospital two, while neurocysticercosis was four times greater in hospital one, strokes were more often present in hospital one too $(P<0.05)$.

The prevalence of the CSP, CV, and CVI was evaluated in the two hospitals separately and thereafter in the whole population from combined samples that grouped the reason for conducting head CT (Table 1). No statistically significant differences were found in the prevalence of the different subtypes of Cavum when one compared the patients who underwent head CT for TBI versus other reasons $(P>0.05)$. When including all subtypes of anatomical ventricular variants, $12.6 \%$ of the patients had at least one type of cavum. However, a remarkable difference in the percentage of anatomical ventricular variants was found between the hospitals: $15.1 \%$ in hospital one versus $7.1 \%$ in hospital two $(P<0.05)$. As depicted in Table 1 , this difference in the prevalence of all types of Cavum was evident when, comparing hospital one against two (i.e., the site containing participants with lower socioeconomic status had the highest percentage of anatomical ventricular variants among all subtypes). The rarest types of Cavum, CV and CVI, were twice more common in hospital one $(P<0.05)$.

The logistic regression analysis (Table 2) confirmed that patients from hospital one were more likely to have any type of Cavum and CSP $(\mathrm{P}<0.05)$. Anatomical brain ventricular variants were also more often observed in patients 72 years old or older, while men were twice more likely to have all forms of ventricular variants $(P<0.05)$.

\section{Discussion}

To our knowledge, this is the first study to report that the prevalence of anatomical variants of the brain ventricles varies according to socioeconomic status, being those anatomic variants more often observed in patients from lower socioeconomic strata.

In our series, about $12.6 \%$ of the patients had at least one type of Cavum (when vestigial CSP are also included). CV and CVI were present in $3 \%$ and $3.5 \%$ of the patients in our series. CSP, and especially CV, when together with CSP, can be markers of brain malformations and neuropsychiatric diseases. Our numbers are also consistent with the same other neuroimaging studies that have evaluated the presence of the different anatomical ventricular variants in different countries[26, 31-33]. In general, cerebral Cavum were more prevalent in countries from Asia and less economically developed[20,21,34]. This is also another evidence that socioeconomic status may be an important risk factor for the development of brain malformations, including cerebral Cavum.

Although not strictly retrospective, the nature of our study prevents us to clear confirm this association, which was only indirectly inferred based on the differences in the distribution of high versus low-cost health insurance and the higher prevalence of neurocysticercosis and cerebrovascular disease in the hospital with the highest percentage of low-cost health insurance. Further studies based on prospective data collection and direct evaluation of salary and additional economic details are mandatory to answer this question. 
Neuropsychiatric diseases are far more prevalent in lower socioeconomic status individuals[35], while CSP and other anatomical variants of brain ventricles are overrepresented in the population with neuropsychiatric diseases[20, 27, 29, 30,36-38]. For instance, persons diagnosed with schizophrenia, alcohol, and victims of TBI have been found to have more frequent, longer, and wider CSP[39, 40]. Also, children diagnosed with Tourette's syndrome may have significantly smaller CSP size; possibly also inversely associated with the severity of attention-deficit/hyperactivity disorder symptom severity[41]. Finally, some robust associations between CSP and interpersonal traits of psychopathy seem to exist both in men and women[37, 42], including during earlier developmental stages in the form of conduct disorder[43], which may point towards a neurodevelopmental disruption within limbic structures with altered threat sensitivity and reduced neural responses during moral processing.

To our knowledge, our present results are also the first study describing the prevalence of cerebral cava in Brazil using a large sample. It is also important to stress, that almost all patients from our series had health insurance. Therefore, it is quite possible that the prevalence of cerebral Cavum is even higher in patients without health insurance or from lower socioeconomic status since most of the Brazilian population does not have private health insurance and must rely on a government-sponsored, public health system.

Another very interesting point that deserves to be stressed is that our study tends to mimic or represent the overall prevalence of cerebral Cavum in the middle and high class in Brazil since the prevalence in the groups with and without TBI were not statistically different. As we have previously pointed out, evaluating the prevalence in patients with TBI would more appropriately reflect the prevalence of cerebral Cavum in the general population, since the evaluation among different populations of patients with neurological diseases would include important bias towards the specific groups of neurological conditions.

Although no major demographic differences occurred between the two hospitals, it is important to emphasize that our results have some important limitations. First, this sample depicts the Brazilian middle-class population. Although both hospitals do accept low-cost health insurance, people from the lowest socioeconomic strata in Brazil were not strongly represented. Second, it would be desirable to directly evaluate each family's income, a variable that unfortunately could not be directly obtained in our

study, considering the retrospective nature consisting in restricted evaluation of collected medical records and request forms. Besides that, this was a cross-sectional evaluation of multislice head CTs. When comparing the neuroimaging literature based on imaging modality (MRI versus CT), CSP including vestigial CSP is less often detected using head CT than MRI. In MRI studies, vestigial CSP in the normal population may reach values around $84,9 \%[37]$ and $83,7 \%[42]$, hence it is possible that this subgroup of vestigial CSP was under-represented in our study.

\section{Conclusion}

In summary, the prevalence of all types of cerebral Cavum (including vestigial CSP) in this middle-class Brazilian population was around $12 \%$. Those anatomical variants of brain ventricles were also more 
prevalent in older male adults with lower socioeconomic status. Further studies are necessary to confirm and evaluate different aspects of the association between socioeconomic status and the prevalence of anatominal varians of brain ventricles.

\section{Abbreviations}

Cavum Septum Pellucidum (CSP)

Cavum Velum Interpositi (CVI)

Cavum Vergae $(\mathrm{CV})$

Traumatic Brain Injury (TBI)

Computerized Tomography (CT)

\section{Declarations}

Ethics approval and consent to participate: This study was approved by the Institutional Review Board from the Research Ethics Committee (CEP) of the Centro Universitário Unichristus (Protocols 099/11 and CAAE: 58763716.3.0000.5049), that granted permission to evaluate all demographic and radiological details from all patients. The Research Ethics Committee (CEP) - Centro Universitário Unichristus provided waiver of informed consent since data was collected from institutional databanks. Data collection for this study respected the principles of research involving human beings, according to all regulatory guidelines and norms.

Consent for publication: Not applicable.

Availability of data and materials: The datasets used and/or analysed during the current study are available from the corresponding author on reasonable request.

Competing interests: The authors declare that they have no competing interests.

Funding: The corresponding author did receive a research scholarship from CNPq (Brazilian National Council for Research) during part of the study.

Authors' contributions: Conceptualization: FAAG; Methodology: FAAG, LPLM; Data Collect: PMGS, AMG, MSS, GAMB, LPLM. Formal analysis and Wrinting. FAAG, LPLM, PMGS. All authors commented on previous versions of the manuscript. All authors read and approved the final manuscript.

Acknowledgements: Not applicable.

\section{References}


1. Udayakumaran S, Onyia CU, Cherkil S. An Analysis of Outcome of Endoscopic Fenestration of Cavum Septum Pellucidum Cyst - More Grey than Black and White? Pediatr Neurosurg. 2017;52:225-33.

2. Sarwar M. The septum pellucidum: Normal and abnormal. American Journal of Neuroradiology. 1989;10.

3. Silk T, Beare R, Crossley L, Rogers K, Emsell L, Catroppa C, et al. Cavum septum pellucidum in pediatric traumatic brain injury. Psychiatry Res - Neuroimaging. 2013;213:186-92. doi:10.1016/j.pscychresns.2013.03.001.

4. Gardner RC, Hess CP, Brus-Ramer M, Possin KL, Cohn-Sheehy BI, Kramer JH, et al. Cavum septum pellucidum in retired American pro-football players. J Neurotrauma. 2016;33.

5. Nakano S, Hojo H, Kataoka K, Yamasaki S. Age related incidence of cavum septi pellucidi and cavum vergae on CT scans of pediatric patients. J Comput Assist Tomogr. 1981;5.

6. Sundarakumar DK, Farley SA, Smith CM, Maravilla KR, Dighe MK, Nixon JN. Absent cavum septum pellucidum: a review with emphasis on associated commissural abnormalities. Pediatr Radiol. 2015;45:950-64.

7. Nopoulos P, Swayze V, Flaum M, Ehrhardt JC, Yuh WTC, Andreasen NC. Cavum septi pellucidi in normals and patients with schizophrenia as detected by magnetic resonance imaging. Biol Psychiatry. 1997;41:1102-8. doi:10.1016/S0006-3223(96)00209-0.

8. Raine A, Lee L, Yang Y, Colletti P. Neurodevelopmental marker for limbic maldevelopment in antisocial personality disorder and psychopathy. Br J Psychiatry. 2010;197:186-92.

9. Sartori P, Anaya V, Montenegro Y, Cayo M, Barba G. ARTICLE IN PRESS Variantes anatómicas del septum pellucidum. 2015; xx:7-12.

10. Saba L, Anzidei M, Raz E, Suri J, Piga M, Grassi R, et al. MR and CT of Brain's Cava. J Neuroimaging. 2013;23.

11. Pearce JMS. Some observations on the septum pellucidum. European Neurology. 2008;59.

12. Shtaya A, Hettige S. Cavum Septum Pellucidum Causing Obstructive Hydrocephalus in a Toddler. Pediatr Neurosurg. 2019;54.

13. Duque-Parra JE. Hypothesis about the genesis of the cavum septi pellucidi in preterm infants and in postnatal life. Rev Neurol. 2004;38:499-500.

14. Brown AS, Deicken RF, Vinogradov S, Kremen WS, Poole JH, Penner JD, et al. Prenatal infection and cavum septum pellucidum in adult schizophrenia. Schizophr Res. 2009;108:285-7. doi:10.1016/j.schres.2008.11.018.

15. Ho YK, Turley M, Marc-Aurele KL, Jones MC, Housman E, Engelkemier D, et al. Enlarged Cavum Septi Pellucidi and Vergae in the Fetus: A Cause for Concern. J Ultrasound Med. 2017;36:1657-68.

16. Dremmen MHG, Bouhuis RH, Blanken LME, Muetzel RL, Vernooij MW, Marroun HE, et al. Cavum septum pellucidum in the general pediatric population and its relation to surrounding brain structure volumes, cognitive function, and emotional or behavioral problems. Am J Neuroradiol. 2019;40. 
17. Bodensteiner JB, Schaefer GB. Wide cavum septum pellucidum: A marker of disturbed brain development. Pediatr Neurol. 1990;6:391-4.

18. Galarza M, Merlo AB, Ingratta A, Albanese EF, Albanese AM. Cavum Septum Pellucidum and Its Increased Prevalence in Schizophrenia: A Neuroembryological Classification. J Neuropsychiatry Clin Neurosci. 2004;16.

19. Trzesniak C, Oliveira IR, Kempton MJ, Galvão-de Almeida A, Chagas MHN, Ferrari MCF, et al. Are cavum septum pellucidum abnormalities more common in schizophrenia spectrum disorders? A systematic review and meta-analysis. Schizophrenia Research. 2011;125.

20. Srivastava NK, Khanra S, Chail V, Khess C. Clinical correlates of enlarged cavum septum pellucidum in schizophrenia: A revisit through computed tomography. Asian J Psychiatr. 2015;15.

21. Khanra S, Srivastava NK, Chail V, Khess C. Prevalence and characteristics of cavum septum pellucidum in schizophrenia: A 16 slice computed tomography study. Indian J Psychol Med. 2016;38.

22. Beraldi GH, Prado KS, Amann BL, Radua J, Friedman L, Elkis H. Meta-analyses of cavum septum pellucidum in mood disorders in comparison with healthy controls or schizophrenia. Eur Neuropsychopharmacol. 2018;28.

23. Wang LX, Li P, He H, Guo F, Tian P, Li C, et al. The prevalence of cavum septum pellucidum in mental disorders revealed by MRI: A meta-analysis. J Neuropsychiatry Clin Neurosci. 2020;32.

24. Trzesniak C, Schaufelberger MS, Duran FLS, Santos LC, Rosa PGP, McGuire PK, et al. Longitudinal follow-up of cavum septum pellucidum and adhesio interthalamica alterations in first-episode psychosis: A population-based MRI study. Psychol Med. 2012;42.

25. Liu H, Li L, Shen L, Wang X, Hou Y, Zhao Z, et al. Cavum septum pellucidum and first-episode psychosis: A meta-Analysis. PLoS One. 2017;12.

26. Toivonen P, Könönen M, Niskanen E, Vaurio O, Repo-Tiihonen E, Seppänen A, et al. Cavum septum pellucidum and psychopathy. Br J Psychiatry. 2013;203:152-3.

27. Landin-Romero R, Amann BL, Sarró S, Guerrero-Pedraza A, Vicens V, Rodriguez-Cano E, et al. Midline Brain Abnormalities Across Psychotic and Mood Disorders. Schizophr Bull. 2016;42.

28. Martins LPL, Sales PMG, Gomes AM, Gondim F de AA. "ON THE RELATIONSHIP BETWEEN THE PREVALENCE OF CEREBRAL CAVA AND SOCIOECONOMIC STATUS." In: XXVIII Congresso Brasileiro de Neurologia/ XV Congresso Panamericano de Neurología/ II International Tropical Neurology Congress. 2018. p. POSTER.

29. Nopoulos PC, Giedd JN, Andreasen NC, Rapoport JL. Frequency and severity of enlarged cavum septi pellucidi in childhood- onset schizophrenia. Am J Psychiatry. 1998;155.

30. Filipović B, Teofilovski-Parapid G. Linear parameters of normal and abnormal cava septi pellucidi: A post-mortem study. Clin Anat. 2004;17.

31. Macpherson P, Teasdale E. CT demonstration of a 5th ventricle-a finding to KO boxers? Neuroradiology. 1988;30. 
32. Aldur MM, Gürcan F, Başar R, Akşit MD. Frequency of septum pellucidum anomalies in non-psychotic population: A magnetic resonance imaging study. Surg Radiol Anat. 1999;21.

33. Akgün Z, Gümüsburun E, Akgün M, Göksel HM, Yücel F. Abnormalities of the Midline Cavities of the Brain: A Computerized Tomography Study. Turkish J Med Sci. 2000;30:271-4.

34. Akinola RA, Idowu OE, Nelson-Paseda AO. Caval variations in neurologically diseased patients. Acta Radiol Short Reports. 2014;3.

35. Patel V. Mental health in low- and middle-income countries. British Medical Bulletin. 2007;81-82.

36. Choi JS, Kang DH, Park JY, Jung WH, Choi CH, Chon MW, et al. Cavum septum pellucidum in subjects at ultra-high risk for psychosis: Compared with first-degree relatives of patients with schizophrenia and healthy volunteers. Prog Neuro-Psychopharmacology Biol Psychiatry. 2008;32.

37. Crooks D, Anderson NE, Widdows M, Petseva N, Decety J, Pluto C, et al. The relationship between cavum septum pellucidum and psychopathic traits in female offenders. Behav Brain Res. 2019;359 June:967-72. doi:10.1016/j.bbr.2018.06.011.

38. Hwang J, Kim JE, Kaufman MJ, Renshaw PF, Yoon S, Yurgelun-Todd DA, et al. Enlarged Cavum Septum Pellucidum as a Neurodevelopmental Marker in Adolescent-Onset Opiate Dependence. PLoS One. 2013;8.

39. Filipović B, Prostran M, Ilanković N, Filipović B. Predictive potential of cavum septi pellucidi (CSP) in schizophrenics, alcoholics and persons with past head trauma: A post-mortem study. Eur Arch Psychiatry Clin Neurosci. 2004;254.

40. Filipovic B, llankovic N, Radonjic V, Filipovic B, Nikolic V. Large cava septi pellucidi in schizophrenic patients, alcoholics, head-traumatized, and normal individuals: Morpholgical features and forensic implications. A postmortem study. Acta Neuropsychiatr. 2006;18.

41. Kim KJ, Peterson BS. Cavum septi pellucidi in Tourette syndrome. Biol Psychiatry. 2003;54.

42. Crooks D, Anderson NE, Widdows M, Petseva N, Koenigs M, Pluto C, et al. The relationship between cavum septum pellucidum and psychopathic traits in a large forensic sample. Neuropsychologia. 2018;112.

43. Blair RJR, Zhang R. Recent neuro-imaging findings with respect to conduct disorder, callousunemotional traits and psychopathy. Current Opinion in Psychiatry. 2020;33.

\section{Tables}

Table 1. Sociodemographic parameters and neuroimaging findings observed in the two samples 
Hospital 1 Hospital 2 Combined

\begin{tabular}{llll}
\hline Number of patients & 1016.0 & 451.0 & 1467.0 \\
\hline Male gender (\%) & 43.3 & 37.9 & 41.6 \\
\hline Age (Mean + SEM) & $55.7 \pm 0.7$ & $56.4 \pm 1$ & $56 \pm 0.6$ \\
\hline Men & $52.1 \pm 0.7$ & $53 \pm 1$ & $52.5 \pm 0.6$ \\
\hline Women & $58.5 \pm 0.7^{\#}$ & $58.4 \pm 1.1^{\#}$ & $58.5 \pm 0.6^{\#}$ \\
\hline High-cost Insurance (\%) & $42.6^{*}$ & 60.8 & 48.1
\end{tabular}

Reason for head CT (\%)

\begin{tabular}{llll}
\hline Head trauma & $35.6^{*}$ & 49.2 & 39.8 \\
\hline Stroke & $17.1^{\star}$ & 6.4 & 13.8 \\
\hline Headache & 24.9 & 29.0 & 26.2 \\
\hline Seizure & 6.5 & 2.4 & 5.3 \\
\hline Other & 24.4 & 18.4 & 22.6 \\
\hline
\end{tabular}

Head CT Findings (\%)

\begin{tabular}{llll}
\hline Stroke & $17.0^{\star}$ & $3.1^{\star}$ & 12.7 \\
\hline Lacunar stroke & $16.2^{\star}$ & $7.1^{\star}$ & 13.4 \\
\hline Subdural hematoma & 2.2 & 0.9 & 1.8 \\
\hline Neurocysticercosis & $3.6^{\star}$ & 0.9 & 2.7
\end{tabular}

\section{Cava variants (\%)}

\begin{tabular}{llll}
\hline Any cava & $15.1^{*}$ & 7.1 & 12.6 \\
\hline Vestigial CSP & $4.3^{*}$ & 1.6 & 3.5 \\
\hline Large CSP & 1.7 & 1.9 & 1.7 \\
\hline All CSP & $6^{*}$ & 3.5 & 5.2 \\
\hline Cavum vergae & $3.6^{*}$ & 1.6 & 3.0 \\
\hline CSP plus cavum vergae & 2.6 & 1.3 & 2.2 \\
\hline Cavum veli interpositi & $4.2^{*}$ & 2.0 & 3.5 \\
\hline & Page 11/14 & & \\
\hline
\end{tabular}


CSP: Cavum septum pellucidum; "Wilcoxon test men versus women (same institution), $\mathrm{P}<0.05$; *Fischer exact test, Hospital 1 versus Hospital 2, $\mathrm{P}<0.05$

Table 2. Logistic regression to evaluate variables influencing the prevalence of anatomic variants in the two samples* 
Variables

Any cava

Large CSP

All CSP variants

(vestigial and large)

\begin{tabular}{|c|c|c|c|c|c|c|c|c|c|}
\hline $\begin{array}{l}\text { Combined } \\
\text { sample }\end{array}$ & $\begin{array}{l}P \\
\text { value }\end{array}$ & OR & $\mathrm{Cl}$ & $\begin{array}{l}P \\
\text { value }\end{array}$ & OR & $\mathrm{Cl}$ & $\begin{array}{l}P \\
\text { value }\end{array}$ & OR & $\mathrm{Cl}$ \\
\hline 2) Hospital (1 vs. & $<0.001$ & 2.34 & $\begin{array}{l}1.56- \\
3.51\end{array}$ & 0.092 & 1.63 & $\begin{array}{l}0.92- \\
2.89\end{array}$ & 0.002 & 2.13 & $\begin{array}{l}1.33- \\
3.42\end{array}$ \\
\hline Gender (Male) & 0.575 & 1.10 & $\begin{array}{l}0.80- \\
1.51\end{array}$ & 0.029 & 1.68 & $\begin{array}{l}1.05- \\
2.68\end{array}$ & 0.018 & 1.56 & $\begin{array}{l}1.08- \\
2.27\end{array}$ \\
\hline Age (41-71) & 0.026 & 1.64 & $\begin{array}{l}1.06- \\
2.53\end{array}$ & 0.266 & 1.44 & $\begin{array}{l}0.76- \\
2.74\end{array}$ & 0.030 & 1.78 & $\begin{array}{l}1.06- \\
3.00\end{array}$ \\
\hline Age $(\geq 72)$ & $<0.001$ & 2.68 & $\begin{array}{l}1.79- \\
4.04\end{array}$ & 0.004 & 2.42 & $\begin{array}{l}1.33- \\
4.38\end{array}$ & $<0.001$ & 2.94 & $\begin{array}{l}1.80- \\
4.79\end{array}$ \\
\hline Head trauma & 0.575 & 1.10 & $\begin{array}{l}0.79- \\
1.52\end{array}$ & 0.457 & 0.83 & $\begin{array}{l}0.51- \\
1.35\end{array}$ & 0.709 & 1.08 & $\begin{array}{l}0.74- \\
1.57\end{array}$ \\
\hline
\end{tabular}

\section{Hospital 1}

Gender (Male)

$0.754 \quad 0.94 \quad 0.66-$

1.35

$0.104 \quad 1.55 \quad 0.91-$

2.63

0.12

$1.39 \quad 0.92-$

2.10

Age (41-71)

$0.082 \quad 1.55 \quad 0.95-$

2.53

0.300

1.50

$0.70-$

3.24

$0.023 \quad 2.03$

$1.10-$

3.72

Age $(\geq 72)$

$<0.001 \quad 2.91$

$1.85-$

4.56

$<0.001$

3.07

$1.54-$

6.09

$<0.001 \quad 3.70$

2.11-

6.48

Head trauma

$0.860 \quad 1.03$

$0.72-$

0.627

0.87

$0.50-$

0.837

1.52
$0.68-$

1.61

\section{Hospital 2}

\begin{tabular}{|c|c|c|c|c|c|c|c|c|c|}
\hline Gender (Male) & 0.065 & 2.00 & $\begin{array}{l}0.96- \\
4.18\end{array}$ & 0.146 & 2.13 & $\begin{array}{l}0.77- \\
5.89\end{array}$ & 0.026 & 2.70 & $\begin{array}{l}1.13- \\
6.47\end{array}$ \\
\hline Age (41-71) & 0.255 & 1.73 & $\begin{array}{l}0.67- \\
4.43\end{array}$ & 0.763 & 1.20 & $\begin{array}{l}0.37- \\
3.88\end{array}$ & 0.894 & 1.07 & $\begin{array}{l}0.39- \\
2.98\end{array}$ \\
\hline Age $(\geq 72)$ & 0.261 & 1.77 & $\begin{array}{l}0.66- \\
4.78\end{array}$ & 0.900 & 0.92 & $\begin{array}{l}0.24- \\
3.53\end{array}$ & 0.795 & 1.16 & $\begin{array}{l}0.39- \\
3.45\end{array}$ \\
\hline Head trauma & 0.295 & 1.48 & $\begin{array}{l}0.71- \\
3.10\end{array}$ & 0.623 & 0.78 & $\begin{array}{l}0.28- \\
2.13\end{array}$ & 0.532 & 1.31 & $\begin{array}{l}0.56- \\
3.08\end{array}$ \\
\hline
\end{tabular}

Cl: Confidence interval; CSP: Cavum septum pellucidum; OR: odds ratio 
* This table was originally published in Portuguese at the Dissertation Thesis from Lisboa, LP (2018) Estudo tomográfico da prevalência de cava cerebrais e de outras variantes neuroanatômicas em dois hospitais privados de Fortaleza - Ceará. Universidade Federal do Ceará. 